\section{Revisão sistemática sobre estudos de espacialização da dengue no Brasil}

\section{Systematic review of spatial analysis studies on dengue in Brazil}

José Raimundo de Araújo'

Efigênia Ferreira e Ferreira²

Mauro Henrique Nogueira Guimarães de $\mathrm{Abreu}^{2}$

${ }^{1}$ Universidade do Estado de Minas Gerais

${ }^{2}$ Universidade Federal de Minas Gerais

\section{Resumo}

O presente estudo objetivou realizar uma revisão sistemática sobre estudos de geoprocessamento do vetor da dengue e da doença no Brasil. A busca dos trabalhos foi realizada nas bases de dados Pubmed, Bireme e Scielo. A seleção foi realizada por critérios de inclusão, sendo estes: artigos originais sobre dengue e emprego de técnicas de geoprocessamento, publicados em inglês ou português de 1998 a 2007; trabalhos de finalização de curso; e trabalhos apresentados em congresso. Trabalhos que avaliaram essa doença em outros países foram excluídos. As palavras-chaves utilizadas na identificação dos artigos foram: "distribuição espacial e dengue", "dengue e geoprocessamento", "análise espacial e dengue", "Sistema de Informações Geográficas e dengue” e suas traduções para língua inglesa. Na base de busca do Scielo foram encontrados 15 artigos, dos quais selecionou-se 8; na Pubmed 11 trabalhos foram identificados, dos quais utilizou-se 3; e na Bireme, 20 trabalhos, dos quais selecionou-se 2 . A revisão realizada permitiu analisar 7 estudos de espacialização dos casos de dengue, 5 trabalhos com vetores da dengue e um estudo que avaliou os casos e os vetores, simultaneamente. Foi freqüente a não-utilização de técnicas de geoprocessamento. Aspectos sociais foram freqüentemente associados à distribuição espacial da dengue. Desta forma, concluiuse que os estudos de espacialização da dengue no Brasil, especialmente aqueles que avaliam os seus vetores, subutilizam as ferramentas do geoprocessamento. Os aspectos socioeconômicos são importantes para o entendimento da distribuição espacial da dengue.

Palavras-chaves: Dengue. Revisão sistemática. Epidemiologia. 


\section{Abstract}

The present study aimed to carry out a systematic review of geoprocessing studies on the dengue vector and the disease in Brazil. The search was conducted in the Pubmed and Bireme databases and in Scielo virtual library. The selection was carried out using inclusion criteria, such as: original articles on dengue and the use of geoprocessing techniques, published in English or in Portuguese, from 1998 to 2007; final course works; and studies presented at congresses. Studies which evaluated the disease in other countries were excluded. The key words used were "spatial distribution and dengue", "dengue and geoprocessing", "spatial analysis and dengue", "geographic information system and dengue" and their translations into Portuguese. In the Scielo database search, 15 articles were found, from which 8 were selected; in Pubmed, 11 articles were identified and 3 were selected; and in Bireme 20 articles were found, from which 2 were selected. The present review allowed the analysis of 7 studies on the spatial pattern of dengue cases, 5 studies on dengue vectors and one study that evaluated dengue cases and vectors, simultaneously. The non-utilization of geoprocessing techniques was frequent. Social aspects were frequently associated with the spatial distribution of dengue. The study concludes that spatial analyses of dengue in Brazil, especially those that evaluated vectors, used geoprocessing tools poorly. Socioeconomic aspects are important to understand the spatial distribution of dengue.

Keywords: Dengue. Systematic review. Epidemiology.

\section{Introdução}

A dengue é uma doença considerada como um grave problema de saúde pública nos países em desenvolvimento ${ }^{1}$.

Ainda existem diversas questões a serem esclarecidas sobre a doença, desde a eliminação dos locais onde os mosquitos se reproduzem até o combate à cadeia de transmissão da doença com o desenvolvimento de políticas nacionais de controle da mesma. A distribuição geográfica da dengue tem sido considerada desigual entre os países, $\mathrm{e}$ dentro dos próprios países ${ }^{2}$. A avaliação da distribuição espacial da doença possibilita a geração de hipóteses explicativas sobre a manutenção da condição em algumas áreas geográficas, apesar dos inúmeros esforços para erradicação da doença.

Algumas explicações para a distribuição desigual das doenças ${ }^{3}$ e, especificamente da dengue $^{2,4}$, têm sido dadas a partir da avaliação dos determinantes sociais.

Neste sentido, o geoprocessamento, entendido como um conjunto de técnicas voltadas para a coleta e tratamento de informações espaciais para um objetivo específico, pode ser considerado muito útil na saúde pública ${ }^{5}$. As atividades envolvendo o geoprocessamento são executadas por sistemas específicos mais comumente chamados de Sistemas de Informação Geográfica (SIG). Estes sistemas são destinados ao processamento de dados referenciados geograficamente ou georreferenciados. Desta forma, o SIG é um conjunto de procedimentos utilizados para armazenar e manipular dados georreferenciados ${ }^{6}$. Para a realização dessas análises é necessária a localização geográfica dos eventos estudados, levando a associação das informações dos mapas à base de dados alfanumérica ${ }^{7}$. O SIG não cria dados, mas relaciona os mesmos utilizando um sistema de referências que descreve relações espaciais ${ }^{8}$, sendo que diversos softwares têm sido utilizados para essa finalidade ${ }^{9}$.

Considerando a importância dos estudos de espacialização para o planejamento de ações de saúde coletiva e a escassez de 
trabalhos que sintetizem a literatura sobre essa temática no Brasil, o presente estudo objetivou realizar uma revisão sistemática das pesquisas cujos resultados utilizam técnicas de espacialização para avaliação da doença dengue e de seu vetor no Brasil.

\section{Metodologia}

A metodologia empregada foi a revisão sistemática, que se baseia em estudos primários, utilizando métodos previamente definidos e explícitos para identificar, selecionar e avaliar criticamente pesquisas consideradas relevantes. As revisões sistemáticas também contribuem como suporte teórico-prático, através de pesquisa bibliográfica classificatória ${ }^{10}$.

A Identificação dos artigos foi feita através da busca bibliográfica nos bancos de dados informatizados Pubmed, Bireme e Scielo de 1998 a 2007.

As palavras-chaves utilizadas na identificação dos artigos foram: "distribuição espacial e dengue", "dengue e geoprocessamento", "análise espacial e dengue", "Sistema de Informações Geográfica (SIG) e dengue”, e suas traduções para língua inglesa.

Os critérios de inclusão para a seleção dos artigos foram: artigos originais de pesquisa sobre dengue com utilização de técnicas de espacialização, publicados em português e inglês e estudos apresentados em Congressos e Seminários, dissertações e teses. Os critérios de exclusão foram: artigos relativos à dengue e geoprocessamento não pesquisados no Brasil, editoriais, relatos de casos e revisões da literatura.

\section{Resultados}

O total de artigos identificados nas bases de dados Pubmed, Bireme e Scielo foi igual a, respectivamente, 11, 20 e 15. A partir da aplicação dos critérios de inclusão e exclusão foram selecionados 3, 2 e 8 nas três bases, respectivamente, totalizando 13 estudos originais e distintos.

Os principais achados dos trabalhos identificados na busca sistemática da litera- tura (Quadro 1) serão apresentados a seguir, em ordem cronológica.

Costa e $\mathrm{Natal}^{2}$ analisaram, através de um estudo ecológico, a incidência e variação espacial dos casos de dengue notificados pela Diretoria Regional de Saúde na área urbana de São José do Rio Preto, de janeiro a julho de 1995. Os dados utilizados foram aqueles do censo do IBGE de 1991, e o município foi dividido em áreas diferenciadas de acordo com suas características socioeconômicas. Os determinantes sociais utilizados foram: a presença de canalização de água interna, de coleta de lixo, de ligação sanitária, número de moradores no domicílio, presença de chefes de família, renda da família e grau de escolaridade. Desta forma, os 264 setores foram agrupados, utilizando-se o procedimento de análise de "Cluster" pelo programa SPSS. Foram definidas três unidades ambientais: área de moradores com renda elevada; área de moradores de renda intermediária; e área de moradores de baixa renda. Foram calculados os coeficientes de incidência e a correlação linear entre as variáveis do setor censitário e o coeficiente de incidência. Na área 3, observou-se o coeficiente de incidência de dengue 1,4 vezes maior do que o da cidade como um todo e 2,7 e 4 vezes maior em comparação com as áreas 2 e 1, respectivamente. Também foi identificada uma correlação inversa do coeficiente de incidência com a coleta de lixo. Desta forma, é possível observar uma desigualdade na distribuição da doença na cidade, atingindo de forma inversamente proporcional os padrões econômicos e sociais avaliados.

Rebelo et al. ${ }^{11}$ avaliaram a distribuição de formas adultas e imaturas do Aedes aegypti nas áreas domiciliares e peridomiciliares em 87 dos 136 municípios do Maranhão, nos anos de 1995 e 1996. Os municípios analisados foram agrupados em oito zonas fitogeográficas. Do total de 87 municípios, foram pesquisadas 176 localidades e 480.687 imóveis. Foram encontrados focos do mosquito em $34,4 \%$ dos municípios, em $67,0 \%$ localidades e em $2,1 \%$ imóveis analisados. A avaliação espacial do mosquito é desigual. A 
Quadro 1 - Características dos estudos de espacialização da dengue no Brasil

Chart 1 - Characteristics of spatial analysis studies in Brazil

\begin{tabular}{|c|c|c|c|c|c|}
\hline Autor/Ano & $\begin{array}{l}\text { Escala } \\
\text { Geográfica de } \\
\text { Abrangência }\end{array}$ & $\begin{array}{l}\text { Unidade espacial } \\
\text { de análise }\end{array}$ & $\begin{array}{l}\text { Programa } \\
\text { utilizado }\end{array}$ & $\begin{array}{l}\text { Método de análise dos } \\
\text { resultados }\end{array}$ & Alguns resultados \\
\hline $\begin{array}{l}\text { Costa e Natal, } \\
1998^{2}\end{array}$ & $\begin{array}{l}\text { Municípios de } \\
\text { São José do } \\
\text { Rio Preto }\end{array}$ & $\begin{array}{l}264 \text { setores } \\
\text { censitários } \\
\text { agrupados em } \\
\text { três unidades } \\
\text { geográficas. }\end{array}$ & SPSS & $\begin{array}{l}\text { Análise de agrupamento } \\
\text { através do procedimento } \\
\text { "Quick Cluster". } \\
\text { Cálculo de coeficiente de } \\
\text { incidência de dengue. } \\
\text { Correlação linear entre Cl e } \\
\text { algumas variáveis por setor } \\
\text { censitário. }\end{array}$ & $\begin{array}{l}\text { As três unidades geográficas } \\
\text { distintas (alta, média e } \\
\text { baixa condições de vida) } \\
\text { apresentaram coeficientes } \\
\text { de incidência diferentes. } \\
\text { Há maior incidência da } \\
\text { doença na área com piores } \\
\text { condições de vida. }\end{array}$ \\
\hline $\begin{array}{l}\text { Rebelo et al., } \\
1999^{11}\end{array}$ & $\begin{array}{l}87 \text { de } 136 \\
\text { municípios } \\
\text { que compõem } \\
\text { o Estado do } \\
\text { Maranhão }\end{array}$ & $\begin{array}{l}\text { Os municípios } \\
\text { foram agrupados } \\
\text { em oito zonas } \\
\text { fitogeográficas: } \\
\text { cerrados } \\
\text { meridionais; } \\
\text { Amazônia; } \\
\text { cerrado e } \\
\text { caatinga; } \\
\text { dunas, mangue } \\
\text { e restinga; } \\
\text { campo aluvial } \\
\text { fluviomarinho; } \\
\text { matas, cocais e } \\
\text { cerrados; matas } \\
\text { e cocais; llha de } \\
\text { São Luís. }\end{array}$ & $\begin{array}{l}\text { Não foi } \\
\text { relatada a } \\
\text { utilização } \\
\text { de nenhum } \\
\text { software. }\end{array}$ & $\begin{array}{l}\text { Cálculo de índice de } \\
\text { positividade para Aedes } \\
\text { aegypti. } \\
\text { Nenhuma técnica de } \\
\text { geoprocessamento foi } \\
\text { utilizada. }\end{array}$ & $\begin{array}{l}\text { A despeito da complexidade } \\
\text { de tipos de clima e } \\
\text { vegetação do Maranhão, } \\
\text { todas as áreas estavam } \\
\text { colonizadas pelo Aedes } \\
\text { aegypti. }\end{array}$ \\
\hline $\begin{array}{l}\text { Souza-Santos } \\
\text { e Carvalho, } \\
2000^{12}\end{array}$ & $\begin{array}{l}\text { Bairro do } \\
\text { Galeão, } \\
\text { na llha do } \\
\text { Governador, } \\
\text { Rio de Janeiro }\end{array}$ & $\begin{array}{l}\text { Quatro zonas: } \\
\text { prédios da } \\
\text { INFRAERO; região } \\
\text { residencial; } \\
\text { vilas militares e } \\
\text { favela; perímetro } \\
\text { comercial. }\end{array}$ & $\begin{array}{l}\text { S-plus versão } \\
3.4 \text { com } \\
\text { módulo } \\
\text { espacial }\end{array}$ & $\begin{array}{l}\text { Técnica de alisamento de } \\
\text { Kernel gaussiano. }\end{array}$ & $\begin{array}{l}\text { Foi verificado que a área da } \\
\text { vila militar e favela estava } \\
\text { permanentemente infestada. }\end{array}$ \\
\hline $\begin{array}{l}\text { Barata et al., } \\
2001^{13}\end{array}$ & $\begin{array}{l}\text { Município de } \\
\text { São José do } \\
\text { Rio Preto }\end{array}$ & $\begin{array}{l}\text { Dois setores } \\
\text { censitários } \\
\text { com níveis } \\
\text { socioeconômicos } \\
\text { diferentes. }\end{array}$ & $\begin{array}{l}\text { Não foi } \\
\text { relatada a } \\
\text { utilização } \\
\text { de nenhum } \\
\text { software. }\end{array}$ & $\begin{array}{l}\text { Cálculo de índice de } \\
\text { fêmeas de Aedes aegypti } \\
\text { por residências. } \\
\text { Nenhuma técnica de } \\
\text { geoprocessamento foi } \\
\text { utilizada. }\end{array}$ & $\begin{array}{l}\text { Encontrou-se maior } \\
\text { proporção de fêmeas no } \\
\text { setor com socioeconômico } \\
\text { mais baixo. }\end{array}$ \\
\hline Santos, $2003^{14}$ & $\begin{array}{l}\text { Território } \\
\text { nacional }\end{array}$ & Municípios & $\begin{array}{l}\text { Não foi } \\
\text { relatada a } \\
\text { utilização } \\
\text { de nenhum } \\
\text { software. }\end{array}$ & $\begin{array}{l}\text { Levantamento dos dados } \\
\text { referentes aos índices de } \\
\text { infestação predial e de } \\
\text { Breteu com registros de } \\
\text { Aedes aegypti e Aedes. } \\
\text { albopictus em todo o Brasil. } \\
\text { Nenhuma técnica de } \\
\text { geoprocessamento foi } \\
\text { utilizada. }\end{array}$ & $\begin{array}{l}\text { Apesar de seu relativo } \\
\text { controle, e do fato de vários } \\
\text { estados não apresentarem } \\
\text { qualquer relato, o Aedes } \\
\text { albopictus apresentou uma } \\
\text { expansão acelerada nos } \\
\text { últimos anos especialmente } \\
\text { no Norte e Nordeste do país. } \\
\text { Mesmo a espécie ocorrendo } \\
\text { em áreas onde há o controle } \\
\text { para o Aedes aegypti, ainda } \\
\text { não é vista como vetor a ser } \\
\text { combatido nos programas } \\
\text { de controle de dengue, } \\
\text { interferindo na notificação. }\end{array}$ \\
\hline
\end{tabular}


Quadro 1 - Características dos estudos de espacialização da dengue no Brasil (continuação)

Chart 1 - Characteristics of spatial analysis studies in Brazil (continuation)

\begin{tabular}{|c|c|c|c|c|c|}
\hline Autor/Ano & $\begin{array}{l}\text { Escala } \\
\text { Geográfica de } \\
\text { Abrangência }\end{array}$ & $\begin{array}{l}\text { Unidade espacial } \\
\text { de análise }\end{array}$ & $\begin{array}{l}\text { Programa } \\
\text { utilizado }\end{array}$ & $\begin{array}{l}\text { Método de análise dos } \\
\text { resultados }\end{array}$ & Alguns resultados \\
\hline $\begin{array}{l}\text { Siqueira et al., } \\
2004^{15}\end{array}$ & $\begin{array}{l}\text { Município de } \\
\text { Goiânia }\end{array}$ & $\begin{array}{l}40.000 \\
\text { residências de } \\
\text { um universo } \\
\text { de } 160.000 \text { em } \\
\text { todos os setores } \\
\text { censitários }\end{array}$ & $\begin{array}{l}\text { ArcView GIS } \\
\text { versão } 3.2 \\
\text { e CrimeStat } \\
\text { versão } 2.0\end{array}$ & $\begin{array}{l}\text { Método dual de Kernel } \\
\text { para comparar a densidade } \\
\text { estimada de indivíduos } \\
\text { soropositivos para o } \\
\text { vírus da dengue com } \\
\text { a densidade estimada } \\
\text { da população total. O } \\
\text { cálculo da razão entre } \\
\text { soropositivos e população } \\
\text { revela a distribuição } \\
\text { espacial da prevalência } \\
\text { estimada da dengue para a } \\
\text { área estudada. }\end{array}$ & $\begin{array}{l}\text { A taxa de prevalência } \\
\text { foi maior nas periferias e } \\
\text { menores na região central } \\
\text { da cidade. Prevalências } \\
\text { superiores a } 50 \% \text { foram } \\
\text { identificadas na região } \\
\text { nordeste e sudeste do } \\
\text { município. }\end{array}$ \\
\hline $\begin{array}{l}\text { Favier et al., } \\
2005^{16}\end{array}$ & $\begin{array}{l}\text { Municípios } \\
\text { de Brasília e } \\
\text { Belém }\end{array}$ & Sem informação & $\begin{array}{l}\text { Não foi } \\
\text { relatada a } \\
\text { utilização } \\
\text { de nenhum } \\
\text { software }\end{array}$ & $\begin{array}{l}\text { Os dados de epidemias de } \\
\text { dengue nas duas cidades } \\
\text { foram confrontados com } \\
\text { dois modelos teóricos: o } \\
\text { modelo homogêneo e o } \\
\text { modelo heterogêneo. } \\
\text { Nenhuma técnica de } \\
\text { geoprocessamento foi } \\
\text { utilizada. }\end{array}$ & $\begin{array}{l}\text { O modelo homogêneo } \\
\text { assume misturas } \\
\text { homogêneas entre a } \\
\text { população do hospedeiro } \\
\text { e do vetor, é baseado } \\
\text { na hipótese de que } \\
\text { o vetor pode picar } \\
\text { qualquer hospedeiro } \\
\text { com probabilidade } \\
\text { igual. O modelo } \\
\text { heterogêneo é baseado } \\
\text { na heterogeneidade de } \\
\text { contatos. As populações } \\
\text { foram divididas em classes } \\
\text { em relação à doença: } \\
\text { suscetibilidade, incubação } \\
\text { ou exposição, infectado, } \\
\text { imunizado ou removido. O } \\
\text { último modelo mostrou-se } \\
\text { mais útil para a dengue }\end{array}$ \\
\hline $\begin{array}{l}\text { Mondini et al., } \\
2005^{17}\end{array}$ & $\begin{array}{l}\text { Município de } \\
\text { São José do } \\
\text { Rio Preto }\end{array}$ & $\begin{array}{l}432 \text { setores } \\
\text { censitários da } \\
\text { área urbana }\end{array}$ & Maplnfo & $\begin{array}{l}\text { Geocodificação dos casos } \\
\text { de dengue a partir do } \\
\text { eixo dos logradouros e } \\
\text { agrupados segundo os } \\
\text { setores censitários da área } \\
\text { do município. } \\
\text { Foi realizada, ainda, análise } \\
\text { temporal. }\end{array}$ & $\begin{array}{l}\text { Foi identificado um foco } \\
\text { inicial e o espalhamento } \\
\text { da doença para o restante } \\
\text { do município. Além disso, } \\
\text { verificou-se que os casos } \\
\text { de dengue não apresentam } \\
\text { distribuição espacial } \\
\text { uniforme. }\end{array}$ \\
\hline $\begin{array}{l}\text { Barcellos et al., } \\
2005^{18}\end{array}$ & $\begin{array}{l}\text { Município de } \\
\text { Porto Alegre }\end{array}$ & $\begin{array}{l}664 \text { imóveis em } \\
\text { diferentes setores } \\
\text { censitários }\end{array}$ & Crimestat & $\begin{array}{l}\text { Georreferenciamento } \\
\text { dos casos de dengue } \\
\text { através do endereço da } \\
\text { residência, bem como dos } \\
\text { imóveis com a presença } \\
\text { de larvas do Aedes aegypti. } \\
\text { Foi calculada a média } \\
\text { espacial e o traçado de } \\
\text { elipses de desvio padrão } \\
\text { da distribuição espacial dos } \\
\text { eventos, com delimitação } \\
\text { a área envoltória. Foram } \\
\text { calculados } 25 \text { indicadores } \\
\text { sócio-ambientais para cada } \\
\text { setor censitário. } \\
\text { Regressão logística foi } \\
\text { realizada. }\end{array}$ & $\begin{array}{l}\text { A distribuição desigual dos } \\
\text { casos importados de doença } \\
\text { e do vetor foi associada a } \\
\text { particularidades da cidade, } \\
\text { que influenciam a ecologia } \\
\text { do vetor e no risco de } \\
\text { adoecer por dengue. Os } \\
\text { casos ocorreram em áreas } \\
\text { de alta renda e a presença } \\
\text { de vetor foi registrada em } \\
\text { casas com boa estrutura } \\
\text { e saneamento. A variável } \\
\text { renda apresentou associação } \\
\text { com a distribuição de casos } \\
\text { verificados no estudo. }\end{array}$ \\
\hline
\end{tabular}


Quadro 1 - Características dos estudos de espacialização da dengue no Brasil (continuação)

Chart 1 - Characteristics of spatial analysis studies in Brazil (continuation)

\begin{tabular}{|c|c|c|c|c|c|}
\hline Autor/Ano & $\begin{array}{l}\text { Escala } \\
\text { Geográfica de } \\
\text { Abrangência }\end{array}$ & $\begin{array}{l}\text { Unidade espacial } \\
\text { de análise }\end{array}$ & $\begin{array}{l}\text { Programa } \\
\text { utilizado }\end{array}$ & $\begin{array}{l}\text { Método de análise dos } \\
\text { resultados }\end{array}$ & Alguns resultados \\
\hline $\begin{array}{l}\text { Caiaffa et al., } \\
2005^{19}\end{array}$ & $\begin{array}{l}\text { Município de } \\
\text { Belo Horizonte }\end{array}$ & $\begin{array}{l}80 \text { unidades de } \\
\text { planejamento, } \\
\text { criadas pela } \\
\text { Prefeitura a partir } \\
\text { de características } \\
\text { sociais e } \\
\text { econômicas. }\end{array}$ & Maplnfo & $\begin{array}{l}\text { Foi realizado o } \\
\text { georreferenciamento da } \\
\text { distribuição de casos de } \\
\text { dengue. }\end{array}$ & $\begin{array}{l}\text { Os maiores índices dengue } \\
\text { foram encontrados em locais } \\
\text { em que havia aglomerações } \\
\text { de residência com indivíduos } \\
\text { de baixa renda. }\end{array}$ \\
\hline $\begin{array}{l}\text { Teixeira et al., } \\
2005^{20}\end{array}$ & $\begin{array}{l}\text { Território } \\
\text { Nacional }\end{array}$ & Macrorregiões & $\begin{array}{l}\text { Não foi } \\
\text { relatada a } \\
\text { utilização } \\
\text { de nenhum } \\
\text { software. }\end{array}$ & $\begin{array}{l}\text { Análise da variação na } \\
\text { incidência e a distribuição } \\
\text { espacial da doença no } \\
\text { território nacional } \\
\text { Nenhuma técnica de } \\
\text { geoprocessamento foi } \\
\text { utilizada. }\end{array}$ & $\begin{array}{l}\text { Nos primeiros anos do } \\
\text { século XXI, o número } \\
\text { de áreas afetadas e a } \\
\text { elevação dos casos de febre } \\
\text { hemorrágica aumentaram } \\
\text { consideravelmente. }\end{array}$ \\
\hline $\begin{array}{l}\text { Lima-Camara } \\
\text { et al., } 2006^{21}\end{array}$ & $\begin{array}{l}\text { Municípios de } \\
\text { Nova Iguaçu e } \\
\text { Rio de Janeiro }\end{array}$ & $\begin{array}{l}\text { Bairros } \\
\text { agrupados em } \\
\text { três categorias: } \\
\text { urbanos, } \\
\text { suburbanos e } \\
\text { rurais. }\end{array}$ & $\begin{array}{l}\text { Não foi } \\
\text { relatada a } \\
\text { utilização } \\
\text { de nenhum } \\
\text { software. }\end{array}$ & $\begin{array}{l}\text { Nenhuma técnica de } \\
\text { geoprocessamento foi } \\
\text { utilizada. } \\
\text { Avaliação dos vetores da } \\
\text { dengue. }\end{array}$ & $\begin{array}{l}\text { Aedes aegypti foi encontrado } \\
\text { com maior freqüência na } \\
\text { área urbana em comparação } \\
\text { à área rural. Enquanto } \\
\text { que o Aedes albopictus } \\
\text { foi encontrado com } \\
\text { maior freqüência na área } \\
\text { rural. Foram registradas } \\
\text { diferenças na distribuição } \\
\text { peridomiciliar e domiciliar, } \\
\text { encontrando-se com maior } \\
\text { freqüência Aedes aegypti } \\
\text { no ambiente domiciliar } \\
\text { e o Aedes albopictus no } \\
\text { ambiente peridomiciliar. }\end{array}$ \\
\hline $\begin{array}{l}\text { Almeida et al., } \\
2007^{22}\end{array}$ & $\begin{array}{l}\text { Município de } \\
\text { Belo Horizonte }\end{array}$ & $\begin{array}{l}\text { Endereço dos } \\
\text { doentes e setor } \\
\text { censitário. }\end{array}$ & $\begin{array}{l}\text { Maplnfo e } \\
\text { SPSS }\end{array}$ & $\begin{array}{l}\text { Utilização de dados } \\
\text { secundários. } \\
\text { Regressão logística foi } \\
\text { realizada. }\end{array}$ & $\begin{array}{l}\text { Variáveis socioeconômicas } \\
\text { explicam as diferenças } \\
\text { nos níveis de doença } \\
\text { identificados no município. }\end{array}$ \\
\hline
\end{tabular}

proporção de municípios com focos de $A e$ des Aegypti foi igual a 70,6\%, 46,7\% e 45,5\% nos cerrados meridionais, na Amazônia Maranhense e nas áreas mistas de matas, cerrados e cocais, respectivamente. Na zona de campo aluvial fluviomarinho, o índice foi de apenas $1,2 \%$. Por outro lado, na Ilha de São Luís, $84,0 \%$ das localidades avaliadas estavam positivas para o vetor.

O objetivo do estudo, descrito por Souza-Santos; Carvalho ${ }^{12}$ foi analisar a distribuição dos criadouros de Aedes aegypti no Bairro do Galeão, na Ilha do Governador, no Estado do Rio de Janeiro, no período de junho de 1992 a julho de 1994. Para tanto, foram descritos os locais onde funcionários da Fundação Nacional de Saúde encontraram larvas dos mosquitos durante este período. A área estudada foi dividida em quatro setores diferenciados (A, B, C e D), e no croqui do bairro foram definidos os 124 quarteirões onde foi realizado o georreferenciamento das áreas positivas para a larva. Para a avaliação dos dados espaciais utilizou-se o programa S-plus, versão 3.4 com módulo espacial, em que foi realizada interpolação e alisamento através de um Kernel gaussiano, calculando-se a probabilidade da ocorrência de larvas em cada setor. A largura de banda utilizada foi de 
300 metros, baseada na área de dispersão do mosquito. Dois métodos de alisamento por Kernel foram empregados para verificar o grau de infestação e a distribuição das residências na área avaliada. Através desta técnica foi obtida a intensidade de quarteirões positivos e a intensidade de risco de transmissão de dengue. No primeiro ciclo foram observadas larvas nas áreas C e D; no segundo ciclo ocorrência nas quatro áreas, com incidência menor na área $\mathrm{D}$, repetindo o perfil das demais. Os autores ressaltaram a ocorrência permanente de larvas nas áreas da região da favela e da vila militar, visto exibirem áreas propícias para o desenvolvimento do vetor.

Barata et al..$^{13}$ avaliaram, entre outros, a distribuição espacial do Aedes aegypti em São José do Rio Preto. Para tanto, inicialmente, a cidade foi setorizada em conjuntos homogêneos, onde foram coletados amostras do vetor nos setores censitários 5 e 9. Os setores escolhidos apresentaram condições socioeconômicas e concentração populacional diferentes. No setor 5 , que apresentava nível socioeconômico inferior foi realizado o controle químico adulticida e larvicida nos meses de fevereiro e abril, o que não foi realizado no setor 9 . A coleta foi realizada de novembro de 1996 a dezembro de 1997, durante o período diurno (entre 9 e 13h), em áreas intra e peridomiciliar, em 145 casas dos dois setores, utilizando-se aspirador apropriado. Houve um grande predomínio de fêmeas no intradomicílio nos dois setores.

O objetivo do estudo desenvolvido por Santos ${ }^{14}$ foi relatar a distribuição atualizada do A. albopictus no Brasil, no período de 1997 a 2002. Para tanto, foram utilizados os dados da Fundação Nacional de Saúde com os índices de infestação e os dados de localização de larvas e ovos dos mosquitos. O A. albopictus apresentou uma expansão acelerada, desde sua introdução no país. Contudo, ainda não ocorreram relatos nos seguintes Estados: Amapá, Roraima, Acre, Tocantins, Piauí, Ceará e Sergipe, totalizando sete Estados. Em dois Estados, Pará e Alagoas, a ocorrência do mosquito foi registrada em um único município. Mas os autores acreditam que a distribuição desse vetor, nas regiões Norte e Nordeste, pode estar subestimada.

Siqueira et al. ${ }^{15}$ avaliaram os pontos espaciais de análise e os fatores de risco para a ocorrência de dengue na cidade de Goiânia. Para tanto, coletou-se a amostra de sangue de 1.600 indivíduos com idade superior a 5 anos, utilizando três coletas. A cidade de Goiânia foi dividida em nove setores. A técnica de amostragem sistemática foi utilizada para inspeção do vetor. Através de uma seleção aleatória, foram escolhidas $4 \%$ das residências do município para realizar a segunda etapa, que constituiu a coleta de sangue para avaliação sorológica. Foi coletado o sangue de 1.589 indivíduos, a fim de se analisar a prevalência do vírus da dengue e coletar informações de nível individual associadas com a infecção viral. Utilizou-se o censo realizado no ano 2000 pelo IBGE a fim de verificar os indicadores sociais e outros fatores de risco potenciais relacionados com a transmissão da doença, descritos como indicadores baseados na área. $\mathrm{O}$ endereço residencial de cada participante foi geocodificado manualmente em um mapa digital, utilizando-se o software ArcViewGIS versão 3.2, que gerou os pontos de distribuição da análise. A análise estatística estimou a prevalência pelo método Kernel, utilizando-se o software CrimeStat versão 2.0. Verificou-se maior prevalência entre indivíduos jovens e acima de 70 anos, não sendo verificada prevalência diferente comparando-se o sexo. Entre os participantes sobreviventes, as mulheres corresponderam a $2 / 3 \mathrm{da}$ amostra. A taxa de prevalência em relação às macroregiões variou de $23,6 \%$ a $41,6 \%$. As taxas mais elevadas foram identificadas na periferia, e foram significativamente mais altas do que na região central. Foram evidenciados dois hotspots, com estimativa de prevalência superior a $50 \%$ no sudeste e noroeste da cidade, sendo que a prevalência na cidade como um todo variou entre $20 \%$ e 50\%. Em uma análise individual, houve correlação positiva entre soroprevalência e nível de educação nas famílias com his- 
tórico de dengue. Este estudo evidencia a heterogeneidade da transmissão da dengue na cidade de Goiânia, o que pode auxiliar no planejamento espacial de intervenções de controle a doença.

Modelos epidemiológicos teóricos que incluem a questão espacial são raros na literatura científica. Favier et al. ${ }^{16}$ desenvolveram modelos comparativos para os dados de uma epidemia de dengue na ilha de Páscoa no Chile e em Belém e Brasília, no Brasil. O modelo homogêneo é baseado na hipótese clássica que o vetor pode contaminar qualquer hospedeiro com probabilidade igual. No modelo heterogêneo, assume-se que a heterogeneidade de contatos emerge da estrutura da população de vetores e dos hospedeiros em seus domicílios. Considerando que Belém apresentou uma proporção mais alta de casas infestadas, essa cidade apresentou um grau de heterogeneidade menor para a epidemia de dengue. Brasília, por outro lado, apresentava um modelo mais heterogêneo. Os autores concluem que o espaço é uma variável importante para o entendimento da distribuição populacional da dengue no Brasil.

Uma avaliação espacial dos casos de dengue registrados pela Secretaria Municipal de Saúde e Higiene no município de São José do Rio Preto no período de setembro de 1990 a agosto de 2002 foi feita por Mondini et al. ${ }^{17}$. Foram geocodificados 13.998 casos utilizando-se o programa Mapinfo, empregando-se setores censitários como nível de agregação com o intuito de analisar a transmissão do dengue e colaborar com o planejamento das ações de saúde. Os vírus circulantes encontrados até 1995 foram o DEN 1, sendo que, nos períodos subseqüentes foram registrados casos de DEN 2. Entre setembro e dezembro de 1994 foram notificados casos de dengue em quatro setores avaliados. Houve um crescimento progressivo dos casos de dengue, atingindo 270 setores analisados entre janeiro e abril de 1995. Entre 2000 e 2001, foram verificados 6.680 casos autóctones com apenas $6 \%$ dos setores sem registros de dengue. Desta forma, foi possível verificar que os casos de dengue não apresentam distribuição espacial homogênea na região, sendo importante avaliar estas variações com o intuito de traçar estratégias de prevenção de dengue.

O objetivo do estudo desenvolvido por Barcellos et al. ${ }^{18}$ foi avaliar a correlação da distribuição espacial do vetor e dos casos de dengue com aspectos socioeconômicos na cidade de Porto Alegre, no período de janeiro a julho de 2002. Para tanto, os casos foram georreferenciados através do endereço de residência e as casas com a presença de larvas do vetor. Através do programa SIGPoa foi possível georreferenciar 664 imóveis, totalizando 95\% de eficiência. Através do programa Crimestat, os dados foram tratados, determinando-se uma área envoltória em que o número de casos e de focos do mosquito foi maior. Do mesmo modo, foi realizada uma divisão em setores, através de indicadores como condições de habitação, saneamento, nível de renda e escolaridade, com o intuito de avaliar o risco de transmissão da doença. Foram identificados 84 setores censitários com a presença de casos e 313 com a presença do vetor. A presença do vetor foi superior nas áreas sul e leste, com grande dispersão em todo município, em contradição à distribuição dos casos, que foi superior na região central da cidade, com baixa dispersão em outras regiões da cidade. Apenas uma área reduzida, encontrada ao longo do baixo curso do Arroio Dilúvio, apresenta associação entre a presença de vetor e notificação de casos da doença. Os autores mostraram que a distribuição desigual dos casos importados de doença e do vetor foi atribuída a particularidades da cidade que influem na ecologia do vetor e no risco de adoecer por dengue. Os casos ocorreram em áreas de alta renda e a presença de vetor foi registrada em casas com boa estrutura e saneamento. Nos setores em que havia predominância de homens ocorreu menor número de casos de dengue. A variável renda apresentou correlação com a distribuição de casos verificados no estudo.

Caiaffa et al. ${ }^{19}$ avaliaram a distribuição de eventos de saúde diferenciados na cidade 
de Belo Horizonte. Os casos autóctones de dengue em Belo Horizonte, entre 1999 e 2003 , foram georreferenciados nas diferentes áreas: urbanas, suburbanas e rurais, caracterizando-se 80 unidades de acordo com a agregação, características homogêneas, continuidade de ocupação e características socioeconômicas. As proporções e as médias de incidência anual foram calculadas multiplicando-se pelo número de $10 \mathrm{mil}$ habitantes e dividindo-se pelo número de anos de observação. A análise espacial dos dados foi realizada utilizando-se MapInfo e o Stata Software. Os maiores índices de dengue foram encontrados em locais em que havia aglomerações de residência com indivíduos de baixa renda.

Teixeira et al. ${ }^{20}$ estudaram os casos de dengue no Brasil, analisando a variação na incidência e a distribuição espacial da doença. O primeiro caso isolado de dengue foi em Boa Vista, Roraima, em 1981, em que foram isolados os sorotipos DEN $1 \mathrm{e}$ DEN 4. Contudo, a disseminação ocorreu em 1986 no Rio de Janeiro e em alguns locais do Nordeste, em que foram isolados o sorotipo DEN 1. No segundo semestre de 1986, ocorreu declínio no número de casos. Em 1998 ocorreu uma pandemia, com número de casos superior ao ocorrido em 1986, reduzindo significativamente no ano de 1999. O DEN 3 foi isolado no fim do ano de 2000, também no Rio de Janeiro, observando-se 470,1 e 1.735,2 casos para cada 100.000 habitantes. Este sorotipo foi também encontrado no mês subseqüente na Região Sul do país, espalhando-se para 22 dos 27 Estados brasileiros. Ressalta-se que, possivelmente, a redução da população de susceptíveis foi responsável pelo declínio das epidemias. Recentemente, o numero de áreas afetadas e a elevação dos casos de febre hemorrágica aumentou consideravelmente, sendo que o controle do vírus vem sendo realizado através do controle químico do vetor, impedindo desta forma a circulação viral. A falta de uma vacina efetiva e a distribuição do vetor permitem que a dengue seja um problema de saúde pública sempre atual.
O objetivo do estudo desenvolvido por Lima-Camara et al. ${ }^{21}$ foi verificar a distribuição do Aedes aegypti e do A. albopictus através de coletas do vetor em áreas domiciliares e peridomiciliares, da zona urbana, rural e suburbana, nos municípios de Nova Iguaçu e Rio de Janeiro, entre agosto de 2002 a julho de 2004. Para tanto, inicialmente, as áreas foram categorizadas de acordo com o nível de urbanização e saneamento, a densidade populacional humana e a cobertura vegetal. A coleta foi realizada duas vezes por semana, pela manhã, durante uma hora, em seis casas escolhidas de forma aleatória. As coletas apresentaram rodízios em relação aos bairros, contudo, o número de coletadas na área urbana foi superior às demais áreas. Foram realizadas 159 capturas de mosquitos, sendo 61 no ambiente urbano, 45 no suburbano e 53 no rural, realizadas com aspiradores manuais ou elétricos e puçás, de acordo com a possibilidade de emprego dos mesmos. Dos 3.748 mosquitos capturados, $77 \%$ eram A. aegypti e $23 \%$ A. Albopictus, com maior captura de fêmeas. A. Aegypti foi encontrado com maior freqüência na área urbana, em comparação com a área rural. De forma contrária, A. Albopictus foi encontrado com maior freqüência na área rural. Ocorreram diferenças na distribuição peridomiciliar e domiciliar ao se comparar as duas espécies avaliadas, encontrandose com maior freqüência $A$. Aegypti no ambiente domiciliar e A. Albopictus no ambiente peridomiciliar, com comportamento similar tanto em machos como em fêmeas. Contudo, considerando-se apenas o sexo do mosquito, as fêmeas foram encontradas com maior freqüência em ambiente domiciliar quando comparadas aos machos, que tiveram maior freqüência em ambiente peridomiciliar. Desta forma, é possível indicar que A. Albopictus pode participar do ciclo da dengue, mantendo o vírus na natureza.

O objetivo do estudo desenvolvido por Almeida et al..$^{22}$ foi avaliar, na cidade de Belo Horizonte, a associação entre as variáveis socioeconômicas, demográficas e de infraestrutura urbana, bem como as áreas de risco classificadas de acordo com a ocorrên- 
cia de dengue e a transmissão persistente. Para tanto, inicialmente, os dados foram obtidos através do Ministério da Saúde e do censo realizado em 2000. Foram avaliados os dados referentes a saneamento básico, escolaridade, densidade demográfica, proporção entre estabelecimentos comerciais e residenciais e número de habitantes com idade inferior a 10 anos de idade e acima de 64 anos (que constituem o grupo de risco). Os estabelecimentos com locais propícios para a reprodução do mosquito foram registrados como de alto risco. As casas foram georreferenciadas pelo endereço, correlacionando com os dados obtidos pelo censo, utilizando-se o Sistema Geográfico de Informações. Analisaram-se as sete curvas epidêmicas ocorridas entre $1996 \mathrm{e}$ 2002. O software MapInfo foi utilizado para o tratamento dos dados e mapeamento, sendo a análise estatística realizada através do SPSS/PC. Baixa renda e elevado número de pessoas residindo na mesma casa foram associados a risco elevado de dengue.

\section{Discussão}

Estudos de revisão sistemática são importantes para analisar pesquisas desenvolvidas em uma determinada área do conhecimento, facilitando o acesso aos pesquisadores que precisam de uma revisão rápida, além de direcionar estudos futuros. É lícito comentar que a presente revisão apresenta como limitação o fato de não terem sido pesquisadas bases de dados diferentes da Pubmed, Scielo e Bireme. Apesar da conferência das referências de todos os artigos identificados visando minimizar esse viés, este fato pode diminuir a chance de identificação de estudos importantes.

Cook et al. ${ }^{23}$ ressaltam que a técnica da revisão fundamenta-se no conhecimento e qualidade da evidência; envolve a definição do problema clínico, identificação das informações necessárias, condução da busca de estudos na literatura, avaliação crítica da literatura, identificação da aplicabilidade dos dados oriundos dos estudos e a determinação de sua utilização para o paciente.
O presente estudo partiu do entendimento do processo saúde-doença como resultante da posição dos indivíduos no espaço, portanto, estudar esse espaço tornase fundamental para a análise da dengue. A dinâmica das doenças infecciosas sempre se manifestou na história da humanidade, entretanto, o que define o momento atual são a velocidade e a intensidade das transformações e de suas repercussões. As mudanças nos cenários e nos paradigmas demandam igual mudança nas estratégias e táticas de controle de doenças infecciosas. Além disso, os dados de avaliação espacial das doenças permitem traçar estratégias a fim de evitar futuras epidemias da doença ${ }^{24}$.

$\mathrm{O}$ pequeno número de trabalhos sobre espacialização da dengue era esperado. Em revisão sobre análise espacial em saúde, em todo o mundo entre 1999 e 2004 foram identificados apenas 58 estudos. Destes, o Brasil contribuiu com 28 trabalhos $(48,3 \%)^{24}$. Além disso, revisões sistemáticas sobre estudos de geoprocessamento em saúde são, ainda, pouco comuns ${ }^{25,26}$.

A revisão realizada permitiu analisar sete estudos de espacialização dos casos de dengue $^{2,15-17,19,20,22}$, cinco trabalhos com vetores da dengue ${ }^{11-14,21} \mathrm{e}$ um estudo que avaliou os casos e os vetores, simultaneamente ${ }^{18}$.

O Quadro 1 mostra, ainda, a escala geográfica de abrangência, que é a área onde vive o conjunto da população-alvo do estudo e as unidades espaciais de análise que são as subunidades que compõem esta área ${ }^{26}$. As unidades espaciais de análise variaram desde endereços até macrorregiões brasileiras. A Região Sudeste foi a mais investigada.

Dos estudos que analisaram a espacialização dos casos de dengue, dois ${ }^{16,20}(28,6 \%)$ não aplicaram qualquer técnica de geoprocessamento. Entre os estudos com vetores da dengue, quatro ${ }^{11,13,14,21}(80,0 \%)$ não utilizaram qualquer técnica de geoprocessamento. A necessidade de se conhecer os SIG e modelos estatísticos que demandam modelos estatísticos bastante sofisticados ${ }^{24}$ pode explicar a pouca utilização das técnicas de geoprocessamento entre os estudos avalia- 
dos. As vantagens na utilização das técnicas de geoprocessamento envolvem a descrição da população com risco aumentado para a doença, a associação entre dados espaciais e características demográficas, a contribuição para o planejamento de políticas públicas e a avaliação das mesmas ${ }^{5-9,25}$. Desta forma, há necessidade de se avançar, especialmente nos estudos com vetores da dengue, na utilização do geoprocessamento. Apesar das vantagens da técnica, os estudos de geoprocessamento utilizam, freqüentemente, dados secundários e são estudos ecológicos que podem apresentar vieses. Além disso, para se entender a complexidade desta doença, com uma imensa variedade de fatores, estudos que considerem a especificidade de cada área, e não todo um município, por exemplo, ainda são necessários, bem como modelos de predição capazes de identificar o risco em áreas não afetatadas ${ }^{22}$.

A metodologia de georreferenciamento

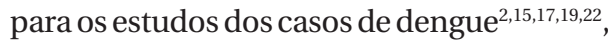
do vetor ${ }^{12}$ e de ambos ${ }^{18}$ utilizou diferentes softwares, mas com análise da distribuição espacial bastante similar. A utilização de setores censitários como nível de agregação é freqüente. Entretanto, análises multivariadas $^{24}$ não foram comuns entre os estudos de geoprocessamento analisados.

A partir dos trabalhos levantados, foi possível verificar que os programas utilizados nos trabalhos para realizar geoprocessamento e avaliação da distribuição geográfica foram: MapInfo, Stata, Crimestat, S-plus e SPSS.

Todos os softwares citados anteriormente são resultantes de compra contínua de sistemas proprietários cada vez mais onerosos. Desta forma, pode-se refletir sobre a dificuldade que os sistemas locais de saúde teriam para adquirir essas ferramentas. Talvez esse seja um dos motivos para o pequeno número de trabalhos publicados sobre geoprocessamento em dengue no nosso país.

Uma alternativa para os sistemas locais de saúde, como é o caso do Sistema Único de Saúde, seria a utilização do software
SPRING (Sistema para Processamento de Informações Georreferenciadas). Esse software foi desenvolvido pelo Instituto Nacional de Pesquisas Espaciais - INPE, sendo livre para o uso público e adequado para estudos de geoprocessamento em diversas áreas, incluindo a saúde pública.

Os resultados dos trabalhos revisados apontam para alguns fatores importantes para a explicação da distribuição da dengue. Dentre esses, pode-se destacar os aspectos sociais $^{2,12,13,15,19,22}$.

Diversos trabalhos têm apontado que, em nível populacional, os fatores sociais têm grande impacto sobre as doenças ${ }^{27-30}$. Parece que a complexa rede de ligação entre os fatores não-biológicos e a dengue também está presente, confirmando outros estudos epidemiológicos ${ }^{4,31}$. A organização do espaço nas sociedades está diretamente ligada à organização social. Assim, melhorias de infra-estrutura urbana, tais como saneamento básico, coleta de lixo, educação, bem como outras que atendam às premissas da promoção da saúde devem ser pensadas de forma intersetorial na construção de políticas públicas que busquem a cidadania $\mathrm{e}$ a qualidade de vida.

Ressalta-se, ainda, a importância de novos estudos que apliquem a técnica de geoprocessamento para a análise da distribuição da dengue, visando o controle desse problema de saúde pública no nosso país. Espera-se que, com a redução dos custos desta informação, com treinamentos de profissionais de saúde nesta área poderá ser ampliado o acesso a essa tecnologia e garantir eficiência nos sistemas de vigilância à saúde ${ }^{24}$.

\section{Conclusões}

Os estudos de espacialização da dengue no Brasil, especialmente aqueles que avaliam os seus vetores, subutilizam as ferramentas do geoprocessamento.

Aspectos socioeconômicos são importantes para o entendimento da distribuição espacial da dengue no Brasil. 


\section{Referências}

1. Brasil. Fundação Nacional de Saúde. Guia de Vigilância Epidemiológica. Brasília; 2002.

2. Costa, AIP, Natal, D. Distribuição espacial da dengue e determinantes socioeconômicos em localidade urbana no sudeste do Brasil. Rev Saúde Pública 1998; 32: 232-7.

3. Kawachi I. What is social epidemiology? Soc Sci Med 2002; 54: 1739-41.

4. Spiegel JM, Bonet M, Ibarra A, Pagliccia N, Quellete V, Yassi A. Social and environmental determinants of Aedes aegypti infestation in Central Havana: results of a case-control study nested in an integrated dengue surveillance programme in Cuba. Trop Med Int Health 2007; 12: 503-10.

5. Rodrigues M. Introdução ao geoprocessamento. In: Simpósio Brasileiro de Geoprocessamento: 1990. São Paulo: Sagres Editora, 1990. p. 1-26.

6. Aronoff S. Geographic Information System. New York: Van Nostrand Reinhold; 1992.

7. Skaba, DA, Carvalho MS, Barcellos C, Martins PC, Terron, SL. Geoprocessamento dos dados da saúde: o tratamento dos endereços. Cad Saúde Pública 2004; 20: 1753-6.

8. Ricketts TC. Geographic Information Systems and Public Health. Annu Rev Public Health 2003; 24: 1-6.

9. Rushton S. Public Health, GIS and spatial analytic tools. Annu Rev Public Health 2003; 24: 43-56.

10. Mulrow CD. Rationale for systematic reviews. BMJ 1994; 309: 597-9.

11. Rebelo JMM, Costa JML, Silva FS, Pereira YNO, Silva JM. Distribuição de Aedes aegypti e do dengue no Estado do Maranhão, Brasil,. Cad Saúde Pública 1999; 15: 477-86.

12. Souza-Santos R, Carvalho MS. Análise da distribuição espacial de larvas de Aedes aegypti na Ilha do Governador, Rio de Janeiro, Brasil. Cad Saúde Pública 2000; 16: 31-42.

13. Barata EAMF, Costa AIP, Chiaravalloti Neto F, Glasser GM, Barata JM, Natal D. População de Aedes aegypti (1.) em área endêmica de dengue, Sudeste do Brasil. Rev Saúde Pública 2001; 35: 237-42.

14. Santos RLC. Atualização da distribuição de Aedes albopictus no Brasil (1997-2002). Rev Saúde Pública 2003: 37: 671-3.

15. Siqueira JB, Martelli CM, Maciel IJ, Oliveira RM, Ribeiro MG, Amorim FP, Moreira BC, Cardoso DD, Souza WV, Andrade AL. Household survey of dengue infection in central Brazil: spatial point pattern analysis and risk factors assessment. Am J Trop Med Hyg 2004; 71: 646-51.
16. Favier C, Schmit D, Muller-Graf CDM, Cazelles B, Degallier N, Mondet B, Dubois MA. Influence of spatial heterogeneity on an emerging infectious disease: the case of dengue epidemics. Proc R Soc B 2005; 272: 11717.

17. Mondini A, Chiavallaroti Neto F, Sanches MGY, Lopes JCC. Análise espacial da transmissão de dengue em cidade de porte médio do interior paulista. Rev Saúde Pública 2005; 39: 444-51.

18. Barcellos C, Pustai AK, Weber MA, Brito, MRV. Identificação de locais com potencial de transmissão de dengue em Porto Alegre através de técnicas de geoprocessamento. Rev Soc Bras Med Trop 2005; 38: 24650 .

19. Caiaffa WT, Almeida MCM, Oliveira CL, Friche AAL, Matos SG, Dias MAS, Cunha MCMC, Pessanha E, Proietti FA. O urbano sob o olhar da saúde: o caso de Belo Horizonte, Minas Gerais, Brasil, Cad Saúde Pública 2005; 21: $958-67$.

20. Teixeira MG, Costa MCN, Barreto ML, Mota E. Dengue e febre hemorrágica do dengue no Brasil: que tipo de pesquisas a sua tendência, vigilância e experiências de controle indicam ser necessárias? Cad Saúde Pública, 2005; 21:1307-15.

21. Lima-Camara TN, Honório NA, Lourenço-de-Oliveira R. Freqüência e distribuição espacial de Aedes aegypti e Aedes albopictus (Diptera, Culicidae) no Rio de Janeiro, Brasil. Cad Saúde Pública 2006; 22: 2079-84.

22. Almeida MCM, Caiaffa WT, Assunção RM, Proietti FA. Spatial vulnerability to dengue in a Brazilian urban area during a 7-year surveillance. J Urb Health 2007; 84: 33445 .

23. Cook DJ, Mulrow CD, Haynes RB. Systematic reviews: synthesis of best evidence for clinical decisions. Ann Intern Med March 1997; 126: 376-80.

24. Carvalho MS, Souza-Santos R. Análise de dados espaciais em saúde pública: métodos, problemas, perspectivas. Cad Saúde Pública, 2005; 21: 361-78.

25. Edelman LS. Using geographic information systems in injury research. J Nurs Scholarsh, 2007; 39: 306-11.

26. Santos SM, Chor D, Werneck GL, Coutinho ESF. Associação entre fatores contextuais e auto-avaliação de saúde: uma revisão sistemática de estudos multinível. Cad Saúde Pública 2007; 23: 2533-54.

27. Buss P. Promoção de saúde e qualidade de vida. Ciência \& Saúde Coletiva, 2000; 5: 163-77.

28. Neri M, Soares W. Desigualdade social e saúde no Brasil. Cad Saúde Pública 2002; 18: 77-87. 
29. Buss P, Pellegrini Filho A. Iniqüidades em saúde no Brasil, nossa mais grave doença: comentários sobre o documento de referência e os trabalhos da Comissão Nacional sobre Determinantes Sociais da Saúde. Cad Saúde Pública 2006; 22: 2005-8.

30. Barata RC. Epidemiologia Social. Rev Bras Epidemiol 2005; 8: 7-17.
31. Guha-Sapir D, Schimmer B. Dengue fever: new paradigms for a changing epidemiology. Emerg Themes Epidemiol 2005; 2: 1-10.

Recebido em: 12/02/08

Versão final reapresentada em: 18/07/08

Aprovado em: 10/10/08 